\title{
Shear Strengthening of RC Beams Using Polyester Rope
}

\author{
Suniti Suparp, Panuwat Joyklad, and Qudeer Hussain
}

\begin{abstract}
This paper presents an experimental investigation on the shear strengthening of reinforced concrete $(\mathrm{RC})$ beams using polyester rope (PR). A total of five small scale $\mathrm{RC}$ beams were cost and tested under four point bending scheme. One beam was tested as un-strengthen to serve as a control beam whereas remaining four beams were strengthened using polyester rope prior to the test. PR was applied in the shear critical region using two different kinds of configurations such as configuration $A$ and $B$. In the configuration $A$, the PR was applied in the form of strips whereas in configuration $B$, the PR was applied over the whole shear critical region of beams. Further in both strengthening configurations, the PR was applied in two different thicknesses i.e., one layer and three layers. The experimental results indicate that use of $P R$ is every effective to alter the response of $\mathrm{RC}$ beams and to enhance the shear strength of RC beams. There is found increase in load carrying capacity with an increase in the PR thickness. It was also observed that strengthening configuration $B$ is superior to the strengthening configuration $A$ in terms of ultimate load carrying capacity of RC beams.
\end{abstract}

Index Terms-Reinforced concrete, shear strengthening, polyester rope, epoxy resin, ultimate load carrying capacity.

\section{INTRODUCTION}

In the past different materials and strengthening techniques such as concrete jacketing, steel jacketing and fiber reinforced polymer composites have been investigated for shear strengthening of reinforced concrete (RC) beams [1]-[3]. Serena Mostosi et. al. 2011 investigated the shear strengthening of RC beams with high performance jackets. In their study the concrete jackets were made with a high performance fiber reinforced concrete, with or without an additional $2 \mathrm{~mm}$ diameter steel-wire mesh. Two different high performance concrete were investigated: a concrete with a self-leveling rheology that can be cast with reduced thickness and a thixotropic material that can be placed without molds. On the basis of experimental results it was concluded that the application of high performance jackets has provided an increase of the maximum load of RC beams and stiffness [4]. Bimal Babu Adhikary et al. 2000 performed experimental and analytical study on shear strengthening of reinforced concrete beams using steel plates bonded on beam web. In their study, two control beams and 10 beams with steel plates bonded to their webs were tested. Steel plates with a continuous length of $2400 \mathrm{~mm}$ and various thicknesses and depths were used. The steel plates were positioned on both sides of the beam

Manuscript received October 1, 2018; revised April 12, 2019.

Suniti Suparp and Panuwat Joyklad are with the Department of Civil and Environmental Engineering, Faculty of Engineering, Srinakharinwirot University, Thailand (e-mail: suniti@g.swu.ac.th, panuwatj@g.swu.ac.th).

Qudeer Hussain is with the School of Civil Engineering, Sirindhorn International Institute of Technology, Thammasat University, Thailand (Corresponding Author: e-mail: qudeer@siit.tu.ac.th). web with a clearance of $2 \mathrm{~mm}$ between the concrete face and the steel plate. In order to fix the steel plates tightly to the beams, expansion anchors were used. The gap around three sides of the plates were sealed with sealing tape, and epoxy adhesive was slowly poured into the space between the plate and the concrete. It was observed that the ultimate shear strength of a beam with a web-bonded steel plate increases with increasing plate depth and thickness across the beam section. It was also found that beams should be reinforced with plates up to maximum possible sectional depth to attain the maximum shear contribution from the plate and to improve the flexural rigidity of the beams [5]. Daniel Baggio et. al. 2014 investigated the strengthening of shear critical RC beams with various FRP systems. The FRP strengthening system were consisted of FRP sheets or fiber reinforced cementitious matrix (FRCM) grid. Nine RC shear deficient slender beams were tested. The experimental results revealed that applying FRP sheets increased the overall shear capacity, full depth u-wrapped FRP sheets perform better over companion partial depth u-wrapped FRP sheets, the use of FRP anchors further improved the shear capacity and ductility of failure, FRP strengthening could change the mode of failure from a shear to flexural failure and FRP de-bonding was delayed with the presence of FRP anchors [6].

In contrast to concrete jacketing, steel plate jacketing and FRP strengthening, recently some researchers had introduced low cost and sustainable materials such as kenaf, flax, jute, sisal and hemp for the strengthening of RC beams [7]-[13]. Md. Ashraful Alam et al. 2018 investigated the possibility to use the kenaf fiber reinforced polymer laminate for shear strengthening of reinforced concrete structures. For strengthening of RC beam, KFRP laminate shear strips were fabricated with $25 \%$ fiber content. Three reinforced concrete beam specimens with the dimension of $150 \mathrm{~mm} \times 300 \mathrm{~mm} \times$ $2,300 \mathrm{~mm}$ were prepared for experimental investigations. One was prepared as control specimen and another two were strengthened for shear using KFRP and CFRP laminates respectively. The results indicate that tensile strength of KFRP laminate increased with the increasing of fiber content. The $25 \%$ fiber content showed the highest tensile strength of KFRP laminate as compared to other mix ratios without showing honeycombs and air voids. The tensile strength of KFRP laminate with $25 \%$ fiber content was found to be 119.6 $\mathrm{MPa}$ which was 2.7 times higher as compared to epoxy laminate without kenaf fiber [14].

The current study is planned to investigate a novel strengthening technique by using polyester rope (PR) for shear strengthening of RC beams. Polyester ropes were applied using epoxy resin. 


\section{EXPERIMENTAL PROGRAM}

\section{A. Test Matrix}

In this experimental study, a total of five shear critical RC beams were cost and tested under four point bending scheme. One beam was tested as unstrengthening to serve as control beam whereas remaining four beams were strengthened using polyester rope prior to the test. The research parameters included were PR thickness (one layer, 1L and three layers, $3 \mathrm{~L}$ ) and strengthening configuration (Strengthening configuration A and B). A summary of test matrix is summarized in Table I. The RC beam specimens were designated in such a way to represent research parameters.

TABLE I: EXPERIMENTAL TEST MATRIX

\begin{tabular}{lll}
\multicolumn{3}{c}{ TABLE I: EXPERIMENTAL TEST MATRIX } \\
\hline \hline Beams & $\begin{array}{l}\text { Strengthening } \\
\text { configuration }\end{array}$ & PR thickness \\
\hline 1-CON & - & - \\
2-A-1L & A & 1 Layer \\
3-A-3L & A & 3 Layers \\
4-B-1L & B & 1 Layer \\
5-B-3L & B & 3 Layers \\
\hline \hline
\end{tabular}
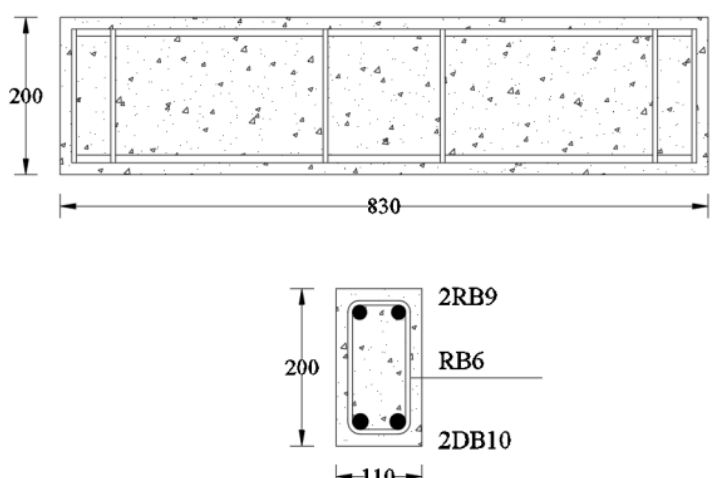

Fig. 1. Details of RC beam (units: $\mathrm{mm}$ ).

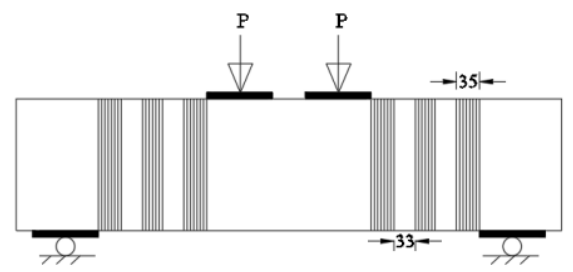

(a)

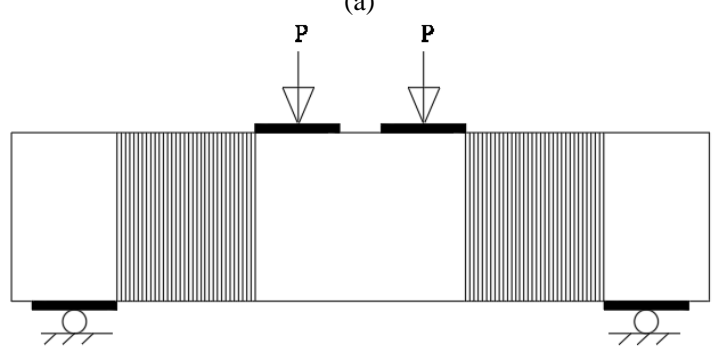

(b)

Fig. 2. Details of strengthening configurations; a) Strengthening configuration A, b) Strengthening configuration B (units: $\mathrm{mm}$ ).

\section{B. RC Beam Specimen Details}

In this experimental study, shear critical RC beams were cost and tested. A schematic diagram of RC beam is shown in Fig. 1. Two round steel bars of diameter $9 \mathrm{~mm}$ were provided at the top and two deformed steel bars of diameter $10 \mathrm{~mm}$ were provided at the tension face. Steel stirrups of round bar with dimeter $6 \mathrm{~mm}$ were provided only at the ends and middle region. In the shear region, stirrups were not provided to induce shear failure.

\section{Strengthening Configurations}

In this experimental two types of strengthening configurations were investigated. The strengthening configurations are shown in Fig. 2. In the configuration A, the PR was applied in the form of vertical strips whereas in configuration $\mathrm{B}$, the PR was applied vertically over the whole shear critical region of beams.

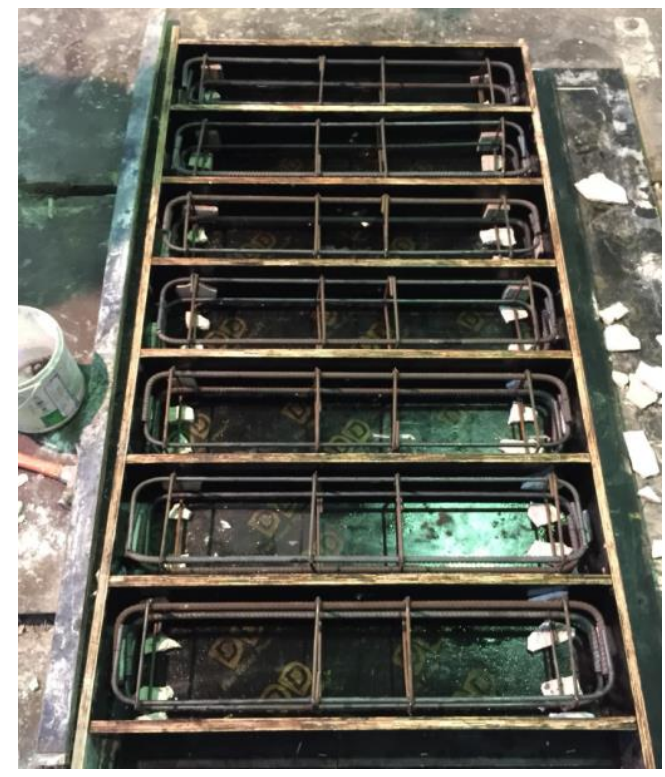

Fig. 3. Construction of RC beams

TABLE II: CONCRETE MIX DETAILS

\begin{tabular}{lll}
\hline \hline Components & Quantity & Units \\
\hline Cement & 242 & $\mathrm{~kg} / \mathrm{m}^{3}$ \\
Sand & 727 & $\mathrm{~kg} / \mathrm{m}^{3}$ \\
Aggregates & 1212 & $\mathrm{~kg} / \mathrm{m}^{3}$ \\
Water & 218 & $\mathrm{~kg} / \mathrm{m}^{3}$ \\
\hline
\end{tabular}

TABLE III: EXPERIMENTAL TEST MATRIX

\begin{tabular}{lll}
\hline \hline Material details & Yield strength $(\mathrm{MPa})$ & $\begin{array}{l}\text { Ultimate strength } \\
(\mathrm{MPa})\end{array}$ \\
\hline RB6 & 250 & 360 \\
RB9 & 300 & 400 \\
DB10 & 340 & 420 \\
PR & - & 76 \\
Epoxy resin & - & 25 \\
\hline \hline
\end{tabular}

\section{Material Properties}

In this experimental program, ordinary Portland cement (OPC) was used to construct RC beam specimens. The concrete was prepared using natural course and fine aggregated with 28 days target compressive strength of 25 MPa. Concrete mix details are provided in the Table II. The yielding and ultimate tensile strength values of steel bars are provided in Table III. Polyester rope was used to strengthen $\mathrm{RC}$ beams. The ultimate tensile strength of PR is also given in table. The PR strengthening was performed using epoxy resin. Epoxy resin is comprised of two parts i.e., part A and part B. 
The mix ratio of epoxy resin is 1:2 (A:B). The strength properties of epoxy resin are given in Table II. The RC beam specimens were cast using plywood sheets as shown in Fig. 3.

\section{E. Strengthening of RC Beams}

PR strengthening of RC beams were performed using epoxy resin. In the first step, the concrete surface of $\mathrm{RC}$ beams was grinded properly to remove loose debris as shown in Fig. 4. In the second step, PR was applied to the RC beams simply by using hand wrap. Then, epoxy resin was applied to the PR by using brush.

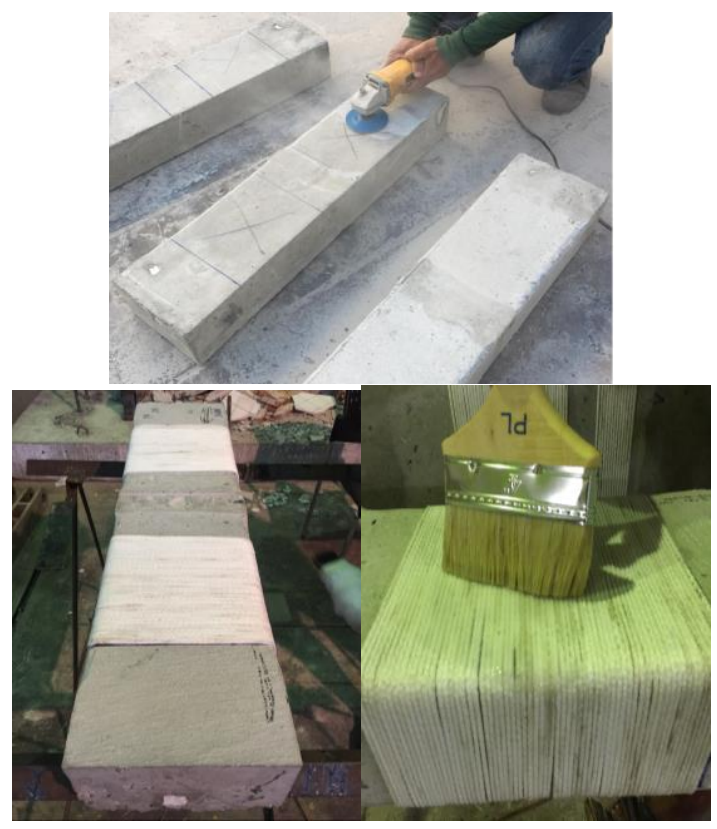

Fig. 4. Grinding of RC beams.

\section{F. Loading Setup}

In this study, both un-strengthened and PR strengthened RC beams were tested under static axial loading as shown in Fig. 5. The load was applied in four point bending scheme at the rate of $1 \mathrm{kN} /$ minute. During the test crack initiation and propagation were observed continuously. Steel plates of thickness $10 \mathrm{~mm}$ were placed at the loading region and supports to avoid local crushing of the concrete. Calibrated load cell and liner variable differential transducers were used to record load intensity and mid span deflections, respectively.



Fig. 5. Schematic diagram of loading setup (units: mm).

\section{EXPERIMENTAL TEST RESUlts}

\section{A. Load Carrying Capacity of RC Beams}

The experimental results in terms of load and mid span deflections are graphically shown in Fig. 6 and summarized in Table IV. It can be seen that ultimate load carrying capacity of un-strengthened RC beam is very low as compared with the PR strengthened RC beams.

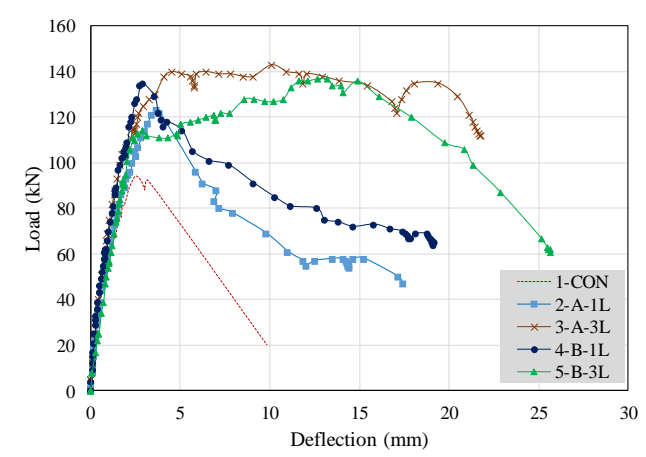

Fig. 6. Experimental results.

TABLE IV: EXPERIMENTAL TEST RESULTS

\begin{tabular}{llll}
\hline \hline Beams & $\begin{array}{l}\text { Ultimate load } \\
(\mathrm{kN})\end{array}$ & $\begin{array}{l}\text { Deflection } \\
(\mathrm{mm})\end{array}$ & $\begin{array}{l}\text { \% Increase in } \\
\text { ultimate load }\end{array}$ \\
\hline 1-CON & 94.0 & 2.50 & - \\
2-A-1L & 123.0 & 3.65 & 31.0 \\
3-A-3L & 143.0 & 10.10 & 52.0 \\
4-B-1L & 135.0 & 2.90 & 44.0 \\
5-B-3L & 137.0 & 12.67 & 46.0 \\
\hline \hline
\end{tabular}

The un-strengthen RC beam specimens 1-CON was failed at an ultimate load of $94 \mathrm{kN}$. The corresponding mid span deflection against ultimate load was observed as $2.50 \mathrm{~mm}$. The experimental results indicate that use of PR is very effective to enhance ultimate load carrying capacity and ductility of the RC beams. The RC beams specimen 2-A-1L, in which a single layer of PR was applied using strength configuration A, was failed at an ultimate load of the $123 \mathrm{kN}$. The ultimate load of this beam specimen is found $31 \%$ higher than the control beam specimens i.e., 1-CON. The mid span deflection of RC beam specimen 2-A-1L is found $3.65 \mathrm{~mm}$ against ultimate load. The RC beams specimen $3-\mathrm{A}-3 \mathrm{~L}$, in which three layers of $\mathrm{PR}$ was applied using strength configuration A, was failed at an ultimate load of the $143 \mathrm{kN}$. The ultimate load of this beam specimen is found $52 \%$ and $21 \%$ higher than the RC beams 1-CON and 2-A-1L, respectively. The mid span deflection of $\mathrm{RC}$ beam specimen 3-A-3L is found $10.10 \mathrm{~mm}$ against ultimate load. The RC beams specimen 4-B-1L, in which a single layer of PR was applied using strength configuration $\mathrm{B}$, was failed at an ultimate load of the $135 \mathrm{kN}$. The ultimate load of this beam specimen is found $44 \%$ higher than the control beam specimens i.e., 1-CON. The mid span deflection of RC beam specimen $4-\mathrm{B}-1 \mathrm{~L}$ is found $2.90 \mathrm{~mm}$ against the ultimate load. The RC beams specimen 5-B-3L, in which three layers of PR was applied using strength configuration $\mathrm{B}$, was failed at an ultimate load of the $137 \mathrm{kN}$. The ultimate load of this beam specimen is found $46 \%$ and $2 \%$ higher than the RC beams 1-CON and 4-B-1L, respectively. The mid span deflection of $\mathrm{RC}$ beam specimen $5-\mathrm{B}-3 \mathrm{~L}$ is found $12.67 \mathrm{~mm}$ against ultimate load. As it can be seen that ultimate load carrying capacity of RC beams strengthened using strengthening configuration $\mathrm{B}$ is higher than that of strengthening configuration A. Further, it is also noticeable that there is an 
increase in the ultimate load carrying capacity of RC beams with an increase in the PR thickness as shown in Fig. 7.

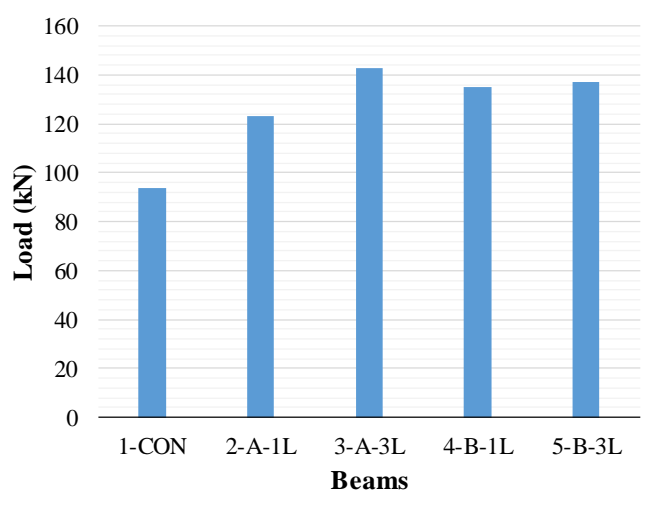

Fig. 7. Ultimate loads of RC beams.

\section{B. Failure Modes of RC Beams}

The ultimate failure modes of $\mathrm{RC}$ beam specimens are shown in Fig. 8-12. It can be seen that un-strengthened RC beam specimens (1-CON) is mainly fail due to the inclined shearing cracks in the shear region as shown in Fig. 8. This kind of failure is very common in shear critical region and also observed in the past literature. The final failure modes of $\mathrm{RC}$ beam specimens strengthened using configuration one layer of PR (2-A-1L and 4-B-1L) were also observed due to the inclined shearing cracks in the shear region, however in these beams the intensity of inclined cracks were found less than that of un-strengthened RC beam specimen i.e., 1-CON (Fig. 9 and 11). The final failure of RC beams specimens 3-A-3L and 5-B-3L was mainly due to the vertical cracks in the middle region as shown in figures. This is mainly due to the PR strengthening of large confinement in the shearing region (Fig. 10 and 12).

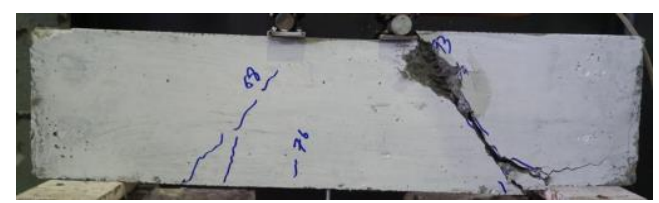

Fig. 8. Failure mode of beam 1-CON.

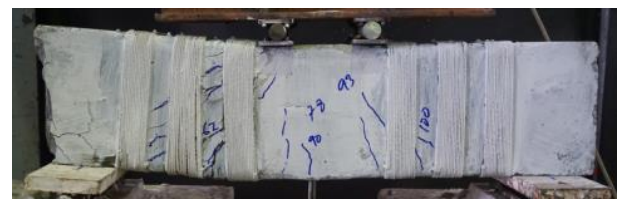

Fig. 9. Failure mode of beam 2-A-1L.

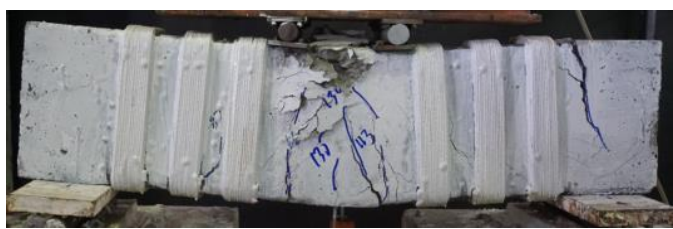

Fig. 10. Failure mode of beam 3-A-3L.

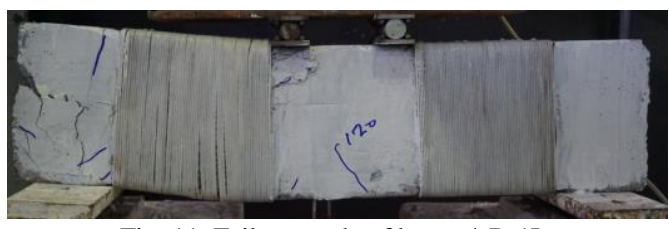

Fig. 11. Failure mode of beam 4-B-1L.

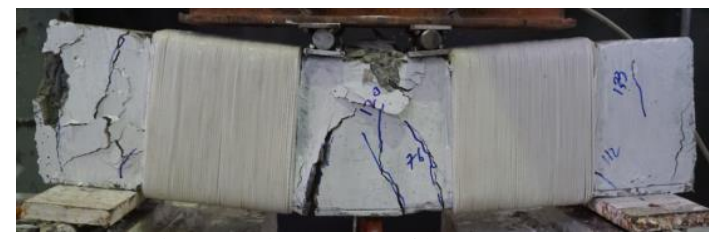

Fig. 12. Failure mode of beam 5-B-3L.

\section{CONCLUSION}

This study presents an experimental investigation on the use of novel technique for the shear strengthening of RC beams. Based on experimental results following conclusions could be drawn;

1) The use of PR is very effective to enhance the ultimate load carrying capacity of shear deficient RC beams.

2) There is found considerable increase in ultimate load carrying capacity of RC beams with an increase in the PR thickness.

3) Both kinds of investigated strengthening configurations are found effective to alter the load carrying capacity of $\mathrm{RC}$ beams, however in comparison, the strengthening configuration $\mathrm{B}$ is found superior to the strengthening configuration A.

\section{ACKNOWLEDGMENT}

The authors would like to thanks Asian Institute of Technology Thailand, for providing test facilities and necessary equipment to carry out this research.

\section{REFERENCES}

[1] R. Jones, R. N. Swamy, and T. H. Ang, "Under- and over-reinforced concrete beams with glued steel plates," The International Journal of Cement Composites and Lightweight Concrete, vol. 4, no. 1, pp. $19-$ 32, 1982.

[2] S. Aykac, I. Kalkan, B. Aykac, S. Karahan, and S. Kayar, "Strengthening and repair of reinforced concrete beams using external steel plates," Journal of Structural Engineering, pp. 929 -939, 2013.

[3] R. N. Swamy, R. Jones, and J. W. Bloxham, "Structural behaviour of reinforced concrete beams strengthened by epoxy-bonded steel plates," Structural Engineer, pp. 59-68, 1987.

[4] S. Mostosi, P. Riva, S. Maringoni, and A. Meda, "Shear strengthening of RC beams with high performance jacket," in Proc. fib Symposium 2011 in Prague: Concrete Engineering for Excellence and Efficiency, 2011.

[5] B. B. Adhikary, H. Mutsuyoshi, and M. Sano, "Shear strengthening of reinforced concrete beams using steel plates bonded on beam web: Experiments and analysis," Construction and Building Materials, vol. 14, no. 5, pp. 237-244, 2000

[6] D. Baggio, K. Soudki, and M. Noel, "Strengthening of shear critical RC beams with various FRP systems," Construction and Building Materials, vol. 66, pp. 634-644, 2004.

[7] M. A. Alam, A. Hassan, and Z. C. Muda, "Development of kenaf fibre reinforced polymer laminate for shear strengthening of reinforced concrete beam," Materials and Structures, vol. 49, no. 3, pp. 795-811, 2016.

[8] T. Sen and H. J. Reddy, "Strengthening of RC beams in flexure using natural jute fibre textile reinforced composite system and its comparative study with CFRP and GFRP strengthening systems," International Journal of Sustainable Built Environment, vol. 2, no. 1, pp. 41-55, 2013.

[9] S. C. Chin, F. S. Tong, S. I. Doh, J. Gimbun, Y. K. Foo, and J. P. Siregar, "Potential external strengthening of reinforced concrete beam using natural fiber composite plate," Applied Mechanics and Materials, vol. 878, pp. 41-48, 2018.

[10] J. Sim and C. Park, "Characteristics of basalt fiber as a strengthening material for concrete structures," Composites Part B: Engineering, vol. 36, pp. 6-7, 2005. 
[11] L. Yan, L. Huang, and H. Braunschweig, "Structural performance of fibre reinforced concrete beams with natural flax FRP strengthening," Structure, 2015.

[12] R. Codispoti, D. V. Oliveira, R. S. Olivito, P. B. Lourenço, and R. Fangueiro, "Mechanical performance of natural fiber-reinforced composites for the strengthening of masonry," Composites Part B: Engineering, vol. 77, pp. 74-83, 2015.

[13] F. S. Tong, S. C. Chin, S. I. Doh, and J. Gimbun, "Natural fiber composites as potential external strengthening material - A review," Indian Journal of Science and Technology, vol. 10, no. 2, 2017.

[14] M. A. Alam and K. A. Riyami, "Shear strengthening of reinforced concrete beam using natural fibre reinforced polymer laminates," Construction and Building Materials, vol. 162, pp. 683-696, 2018.

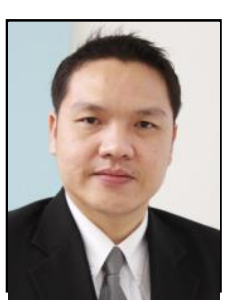

Suniti Suparp is an associate professor with the Department of Civil and Environmental Engineering, Srinakharinwirot University, Thailand.

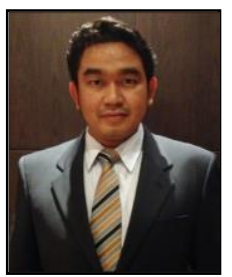

Panuwat Joyklad is an assistant professor with the Department of Civil and Environmental Engineering, Srinakharinwirot University, Thailand.

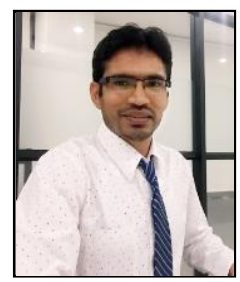

Qudeer Hussain is with School of Civil Engineering, Sirindhorn International Institute of Technology, Thammasat University, Thailand. 